\title{
Visualization Analysis of Research of English for Specific Purposes in China Based on CiteSpace $(2000-2017)^{*}$
}

\author{
Fanghui $\mathrm{Hu}$ \\ School of Foreign Languages, Jining Medical University, Rizhao, Shandong Province, China
}

\begin{abstract}
Based on the data from CNKI database, this study used CiteSpace to analyze the research hotspots and development trends of studies on English for Specific Purposes in China from 2000 to 2017. The results show that research hotspots mainly include college English ESP teaching reform, ESP teaching methods and models, needs analysis and ESP, ESP curriculum provision and curriculum design. The domestic studies on ESP experienced slow development in controversy, rapid development in practice and deep development with modern educational technology. Domestic ESP research has yielded fruitful results, but in the future, research on ESP evaluation system, ESP teachers, ESP corpora development, and ESP textbook construction should be deeply explored.
\end{abstract}

Index Terms - ESP, knowledge mapping, hotspot, trend

\section{INTRODUCTION}

English for Specific Purposes (ESP) is the English relevant to a particular profession or discipline. It is an approach generated by learners' specific needs and it is developed with the development of social needs for English, linguistic theories and educational psychology research (Hutchinson \& Water, 1987). In China, there was little research on ESP until 2000, when relevant scholars debated whether there was "English for science and technology (another term for ESP in China at that time)". Therefore, for quite a long time, scholars believed that college English teaching in China was just a general English teaching, and there was no need or necessity for ESP teaching (Cai, 2004). However, in 1999, the revised "syllabus for college English" formally proposed the concept of "professional English" and stipulated it as a compulsory course, the study of ESP then started a new era. Moreover, with the increasingly close international communication after China's accession to the WTO in 2001, the research achievements of ESP in China had been greatly enriched. The latest college English teaching guide issued by the ministry of education in 2017 clearly pointed out that ESP is one of the main contents of college English teaching. It can be predicted that the study of ESP is bound to set off a climax in the academic circle.

Therefore, it is necessary and timely to sort out the existing studies on ESP in China from 2000 to 2017 in order to guide the future research of ESP in China. At the same time, according to the retrieval and review of relevant literature in the database of China National Knowledge Infrastructure (CNKI), the existing articles about ESP in China are basically based on the summative research, with strong subjectivity. Articles on the research hotspots and trends of ESP in China after 2000 are scarce. In this context, this study attempts to use CiteSpace software to analyze the research on English for Specific Purposes in China from 2000 to 2017, so as to objectively reveal research hotspots and development trends in this field and provide some references for deepening English teaching reform in Chinese universities.

\section{ReSEARCh METhodology}

\section{A. Data Sampling}

In this study, journals in CNKI database were used as the data source. Retrieval subject words were set as ESP and several Chinese translated terms, which were represented by ESP ${ }^{\mathrm{a}}, \mathrm{ESP}^{\mathrm{b}}$ and $\mathrm{ESP}^{\mathrm{c}}$ in the following table or figures. The time zone was set from 2000 to 2017. A total of 7,690 articles were obtained through precise matching retrieval. Then, by reading the title and abstract of the paper, the retrieval results were further deleted and re-deleted. After removal of the meeting notice, academic news introduction, journal introduction and irrelevant items, 4,925 journal articles were finally obtained.

\section{B. Research Tool}

A scientific knowledge map is a series of graphs reflecting the relationship between knowledge development process

\footnotetext{
* This paper is supported by Supporting Fund for Teachers' research of Jining Medical University (JYFC2018RW001) and Research Project of Education and Teaching of Jining Medical University (18081).
} 
and structure. Visualization technology is used to present knowledge and their relationship, providing practical and objective reference for discipline research. In this study, CiteSpace 5.1 R8, a kind of visual analysis software, was used for data processing and drawing of knowledge map of ESP research in China from 2000 to 2017.

\section{Research Procedure}

Firstly, 4,925 papers in refworks format were imported into CiteSpace for format conversion. Then, a new analysis project was established: the time interval was set from 2000 to 2017, with 2 years as a time slice; title, abstract, key words and extended key words were chosen; burst words were selected for the term type; keywords were selected for node type; the contact strength and range were set the default values; and the top 20 high-frequency data of each year were captured. Then, the program was run to generate the knowledge map after pruning operations. Finally, the generated knowledge map was described and analyzed.

\section{RESULTS}

The present study uses bibliometric software for the first time to explore ESP developmental trends and research hotspots, which will be beneficial for future ESP research and ESP teaching in China.

\section{A. General Trend of ESP Research}

Fig. 1 shows that the number of papers published on ESP was less than 100 per year from 2000 to 2006. From 2007 to 2012, the number of published articles greatly increased year by year. From 2013 to 2017, the number of published articles exceeded 500, maintaining a good growth trend. The overall rise in the number of ESP research papers published in China reflects that ESP research has gradually become a hot topic of English teaching in China.

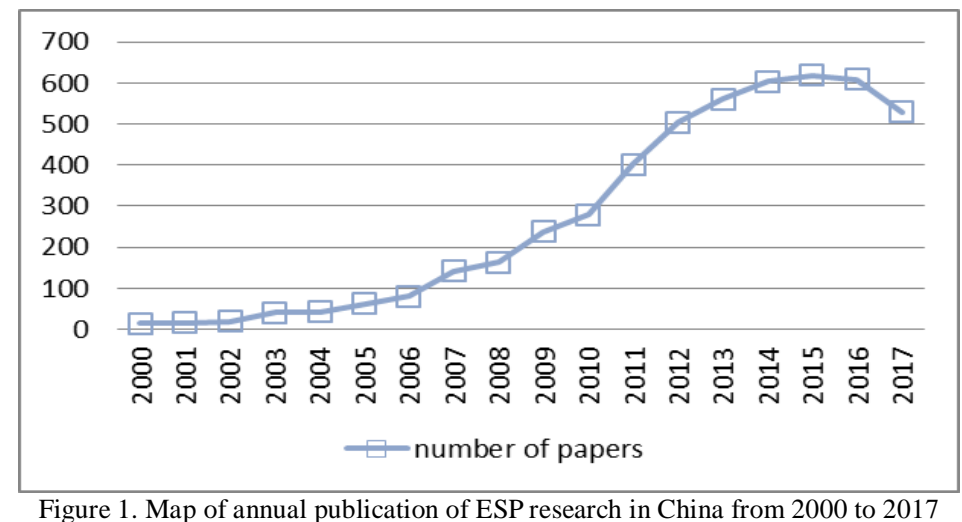

The timezone view can comprehensively present the historical development status or theme evolution path of relevant research topics. From 2000 to 2017, the co-current map of keywords in ESP studies was drawn by CiteSpace, as shown in Fig. 2.

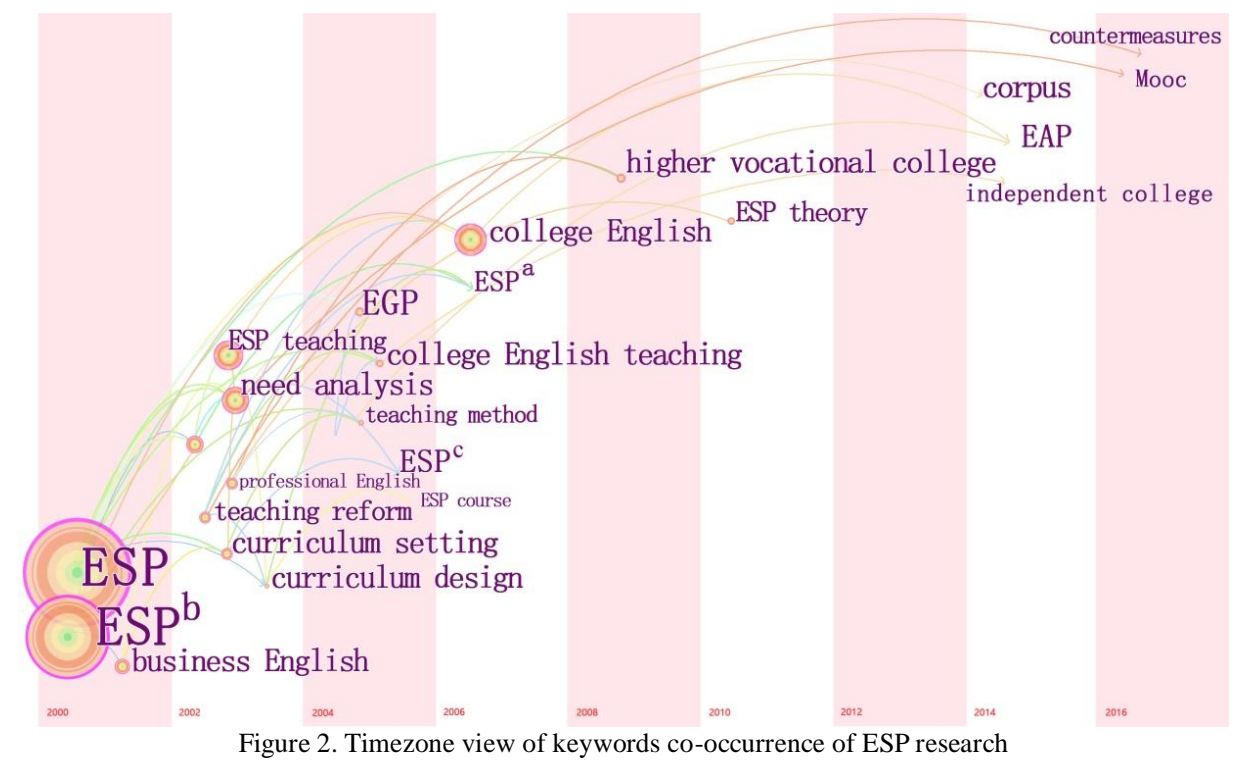

After comprehensive analysis of Fig. 1 and Fig. 2, research trend of ESP in China from 2000 to 2017 shows that ESP research in China experienced three stages. 


\section{Slow development in controversy (2000-2006)}

From 2000 to 2006, ESP research papers are on slow rise, but the total number of papers is 277, only accounting for $5.7 \%$ of all papers. This is due to the debate about whether there existed ESP at the end of last century, which led to the lack of unified and clear understanding of the characteristics and position of ESP at the beginning of the new century, to a great extent, hindering the development of ESP study. However, as is seen in Fig. 2, business English, as an active branch of ESP, had attracted more and more attention during this period with the increasing business activities in the economic globalization. Especially after China's accession to the WTO in 2001, business English, as a tool of international business communication, had been endowed with more functions. Business English had gradually started to develop in various colleges and universities.

In a word, ESP research in China was still in its infant stage and mainly about the introduction of foreign research results (Han, 2003). Compared with the ESP systematic research abroad, domestic research was quite limited. Moreover, most of them were speculative research while practical research was less (Wang, 2004). On the other hand, the development of ESP teaching research represented by business English had played a certain role in promoting the further development of this field.

2. Rapid development with teaching practice (2007-2012)

Fig. 1 shows that between 2007 and 2012, the number of ESP research papers surged year by year, with the total number of papers reaching 1,726, accounting for 35\% of the total. This indicated that ESP research had gradually become a hot topic in this field. As can be seen from Fig. 2, the key words in this stage were mainly ESP theory, higher vocational colleges, and college English, etc. Through a careful study of relevant literature, it is found that a large deal of teaching practice was carried out in this stage based on ESP theory and ESP teaching model (Huang, 2011; Zhang, 2011). In particular, the research and teaching practices of English for Occupational English (EOP) in higher vocational colleges and universities, which were aimed at cultivating skilled and applied talents, came to a climax (Zhang, 2008).

The main reasons for the rapid development of ESP in China at this stage were as follows. First, ESP was basically recognized as the direction of college English teaching reform due to the theoretical contention in the previous phase, which provided a clear rationale for ESP teaching. Second, it benefited from the promulgation of relevant policies of the ministry of education. For example, in 2005, the ministry of education issued the "decision of the state council on vigorous developing vocational education", which required employment-orientation of education reform. This would certainly promote the development of EOP teaching in higher vocational colleges. In 2007, "college English teaching requirements" was issued, which indicated the requirements for students' professional reading ability. Third, it benefited from the holding of ESP research seminars, and establishment of specialized journals and institutions. Since 2009, the international academic conferences "ESP in Asia" and annual meetings have been held in Chinese universities continuously, igniting domestic enthusiasm for ESP research. In 2010, "China ESP research" was officially established. In 2011, the ESP committee of the China foreign language teaching was formally established. All these contributed to the rapid development of ESP in China.

Although at this stage, ESP research in China experienced rapid development, many studies were still not deep enough. ESP teaching effect was not good due to many reasons, such as students' poor English level and the lack of ESP teachers.

3. Deep development with modern educational technology (2013-2017)

Fig. 1 shows that from 2013 to 2017, the number of papers on ESP research maintained at least 500 annually, with a total of 2,921 papers, accounting for 59.3\% of the total. Fig. 2 shows that the major research topics in this stage include English for Academic Purposes (EAP), corpus, Moocs, and countermeasures, etc.

To begin with, EAP is a branch of ESP. With the deep development of ESP research, academic English teaching has become a hot topic in college English teaching reform in China. For example, Cai (2014) argued that English for Academic Purposes is the direction of the reform and development of college English teaching in China. On the other hand, Wang and Yao (2013) pointed out that EAP was worthy of attention, but it should not become the whole content of college English teaching. Then, with the development of modern network information technology in recent years, deep development and reasonable utilization of the foreign language information resources have become the key factors to reform college English teaching mode and teaching content and realize informatization of the foreign language education. Based on modern network and technology, Massive Open Online Courses (Moocs) has sprung up and become a new ESP teaching mode (Wang, Liu \& Fu, 2015). ESP corpus development and research have been increasingly abundant (Li, et. al, 2015). Finally, in this stage, deep analysis of the current research on ESP teaching was carried out to actively reflect on the current problems in ESP teaching in China and seek for relevant countermeasures (Wang, 2016).

In a word, the research achievements in this stage not only advanced by leaps and bounds in quantity, but also improved in quality with development of modern educational technology.

\section{B. Hotspots in ESP Research}

Keywords can generally summarize the core content of the paper. Therefore, by analyzing the frequency of keywords, we can study the research hotspots in a certain research field. The keyword co-occurrence network graph is obtained after CiteSpace operation (as shown in Fig. 3). In the keyword network graph, the size of nodes represents the frequency of their occurrence. The thickness of the lines between nodes indicates the strength of their co-occurrence. 


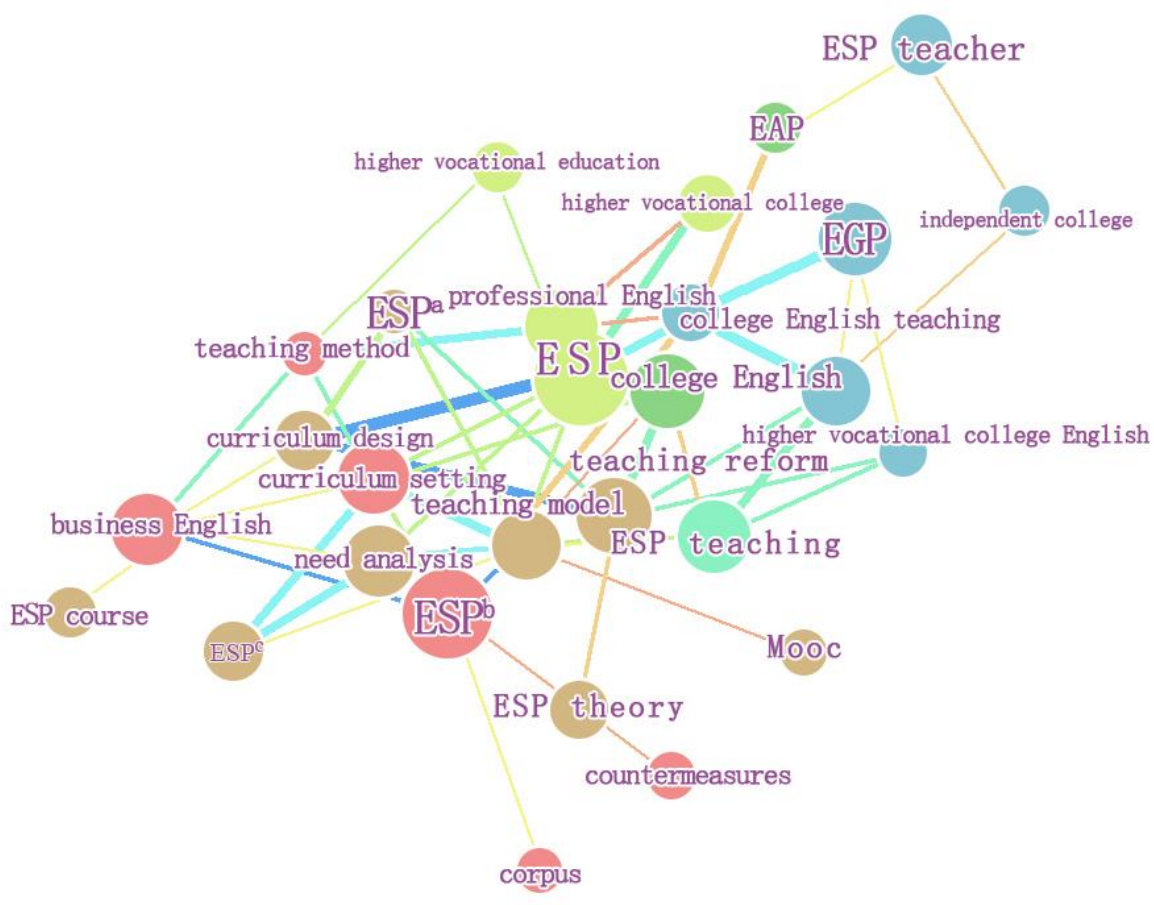

Figure 3. ESP keywords co-occurrence network graph

According to the relevant data generated by CiteSpace after co-word analysis, some keywords with high-frequency and high-centrality are shown in Table I. As can be seen from Table I, some keywords, such as "needs analysis", "teaching model", etc., appear more frequently, and their centrality value is also high. This shows that they are the focus of ESP research in China. Some keywords, such as "teaching reform", "curriculum design" and "teaching method", are relatively infrequent, but their centrality value is relatively high. Since centrality is an index to measure the importance of nodes in a network, these keywords with low frequency but high value of centrality indicate to some extent that they are emerging hotspots in ESP research in recent years.

TABLE I.

KEYWORDS LIST WiTH High FREQUENCY AND HiGH CENTRALITY

\begin{tabular}{ccc}
\hline Keywords & Frequency & Centrality \\
\hline ESP & 1182 & 0.50 \\
ESP $^{\mathrm{b}}$ & 875 & 0.35 \\
College English & 391 & 0.14 \\
ESP teaching & 373 & 0.15 \\
need analysis & 312 & 0.37 \\
teaching model & 240 & 0.46 \\
professional English & 214 & 0.37 \\
business English & 204 & 0.18 \\
English teaching & 202 & 0.22 \\
teaching reform & 198 & 0.73 \\
EGP & 161 & 0.14 \\
curriculum provision & 160 & 0.14 \\
higher vocational college & 129 & 0.18 \\
curriculum design & 80 & 0.70 \\
teaching method & 63 & 0.31 \\
\hline
\end{tabular}

By making a comprehensive analysis of the larger nodes in Fig. 1 and the keyword frequency and centrality in Table I, the research hotspots of ESP in China since the 21st century mainly include the following ones.

1. Reform of ESP in college English teaching

With the rapid development of economic globalization, there is a growing gap between traditional English teaching and social needs, which inevitably leads to reform of college English teaching. Scholars in China have also conducted heated theoretical discussions and practical studies on the reform of college English teaching. Yu \& Han (2012) reviewed the reform process of college English teaching in the 21 st century and then pointed out that content-driven is the core of ESP teaching reform. Fu (2012) discussed the development trend of college English to ESP from the perspectives of social needs, ESP theory, and practical teaching, proposing that college English teaching courses in local colleges and universities should be composed of three modules: basic English, academic English and professional English. In addition, it discussed the transformation of EGP teachers to ESP teachers in local universities under the 
background of the transfer of the focus of college English teaching from EGP to ESP. Li \& Cai (2013) discussed the teaching contents, teaching methods, CET-4 and CET-6 exams and the characteristics of ESP textbooks during the transition from college English to ESP. Li (2017) believes that English teaching should not only reform the EGP and ESP teaching modes, but also reform the management evaluation system.

In a word, after theoretical discussion and practical research on college English teaching reform in China, a general consensus has been reached on the reform and development orientation from college general English teaching to ESP teaching.

2. ESP teaching methods and models

In the process of college English transforming from EGP to ESP, the teaching models and methods related to ESP teaching had inevitably become research hotspots. As the teaching purpose and content of ESP are specialized, it is necessary to adopt specific ESP teaching methods to complete the teaching task. Gu (2006) and Wang (2014) discussed the application of task-based teaching method and project-based teaching method in ESP courses. Luo \& Tong (2009) summarized three teaching methods of ESP (sentence practice method, communicative method and "learner-centered" method). Zhang (2015) elaborated three main implementation steps of cognitive teaching method in ESP teaching. Guo (2014, 2016) summarized ESP teaching methods and analyzed the teaching characteristics of ESP in "post-method era", pointing out that "learning-centered method" is the "post-method" of ESP.

Teaching mode refers to a relatively stable teaching structure and procedure established on a certain theoretical basis to achieve corresponding teaching objectives (Han, Tian \& Yuan, 2012). The development of teaching mode innovation, to a certain extent, determines the success or failure of teaching reform and innovation. Gu (2010) analyzed the existing problems of ESP teaching models in colleges and universities, and came to the conclusion that the traditional teaching model of "translation + reading" was not conducive to cultivating students" practical English ability. With the development of modern information technology, ESP blended teaching model based on network exploration was developed (Zhang, 2013; Chen, 2016). At the same time, ESP teaching model research also focused on business English, medical English, etc. (Zhu, 2010; Liu, 2016).

3. Needs analysis and ESP

Needs analysis is an important part of ESP theory. Hutchinson\& Waters (1987) pointed out that ESP was established on the basis of some needs analysis of students, including target need analysis and learning need analysis. Cai \& Chen (2013) investigated the needs for ESP in the context of internationalization of higher education from three dimensions of students, English teachers and professional teachers with a large sample, so as to discuss the necessity of college English teaching reform. In addition, needs analysis is also a prerequisite to ensure the effectiveness of ESP teaching. Therefore, needs analysis has attracted more and more attention from ESP teaching researchers. Based on needs analysis, research achievements in ESP curriculum setting, teaching model, teaching design, curriculum construction, teacher professional quality and teacher development also began to emerge (Wang, 2012; Li \& Hu, 2014; Guo \& Li, 2015).

4. ESP curriculum setting and curriculum design

Curriculum setting is an important measure to realize the national will and implement educational policies (Yang \&Jin, 2015). As two active branches of ESP, business English curriculum setting and medical English curriculum setting have received special attention (Ma, 2009; Yu \& Liu, 2013). It is also pointed out that the existing ESP curriculum in China was unreasonable or insignificant, which did not achieve the expected effect (Han \& Dong, 2011). Zou (2013) introduced the ESP curriculum and its operation in Taiwan, which provided some inspiration for the ESP curriculum in Chinese universities. Ji (2017) elaborated ESP curriculum setting under the framework of the latest edition of the guide to college English teaching and pointed out that ESP courses, including general academic English, academic English and professional English, could be divided into three levels of foundation, improvement and development. Different types of colleges and universities can offer ESP curriculum according to the requirements of school characteristics and students' needs.

In order to achieve better teaching effect and teaching purpose, good curriculum design is particularly important. Lu (2009) pointed out that the formulation of ESP curriculum design principles and the arrangement of language tasks should focus on the subject knowledge rather than the language knowledge itself. Zhao \& Wang (2015) designed and practiced business English courses based on ESP theory and social constructivism, enriching and developing the existing ESP course design.

\section{DISCUSSION AND IMPLICATION}

\section{A. Summary of Research Results}

Through literature review and knowledge mapping analysis, it is found that ESP research in China, especially the ESP teaching research, has undergone a tortuous development process and meanwhile achieved abundant research results since 2000. It is mainly reflected in the following two aspects:

1. Establishment of ESP

ESP has gone through a process from controversy to consensus in China. Specifically speaking, it developed from the discussion on the positioning and existence basis of ESP in the early 2000s (Chen, 2001) to the debate on the development direction of college English teaching reform (Cai \& Liao, 2010; Wang \& Wang, 2011; Sun \& Li, 2011) to 
the latest guide to the college English teaching issued by the ministry of education in 2017, which clearly put forward ESP is one of the three part of the teaching content in college English, marking ESP teaching being officially recognized in China.

2. Preliminary practice of ESP teaching

In the first decade of this century, ESP has been put into practice after the argument that ESP should be the development direction of college English teaching has been proved for many times (Cai, 2015). As a pioneer of ESP, business English has been continuously developed and improved in the practice (Zhao \& Wang, 2015); reform of some skill classes or some ESP has been carried out (Chen, 2011; Yu, 2011). Practical research on ESP teaching expanded from undergraduate education to higher vocational education (Zhuang, 2009) and postgraduate education (Li, 2016).

3. Establishment of ESP research system

The research achievements of ESP have been fruitful, with the annual output increasing year by year. The research involves needs investigation and analysis of ESP teaching, ESP curriculum setting and teaching model based on the needs analysis (Yu, 2012; Cai \&Ning, 2013), ESP teaching practice based on ESP curriculum setting (Ji, 2017), and ESP teaching material construction related with ESP teaching (Li, 2017), the corpus construction (Zhang, Wang \& Gao, 2009), ESP teachers development (Zhang \& Yuan, 2014; Fu, 2016) and so on. There is both theoretical exploration and teaching practice. Thus, the basic framework and system of ESP research have been preliminarily formed.

\section{B. Suggestions for ESP Research in China}

1. Broadening the scope of ESP research

A review of previous studies shows that there are few high-quality studies (only 319 papers published in CSSCI journals, accounting for $6.5 \%$ of the total number of papers), and more homogenized studies. Moreover, few studies examined the actual teaching effect of ESP curriculum design. In addition, there is a lack of in-depth research on various factors influencing ESP teaching and learning in the process of transformation. There is also a lack of research focusing on ESP professional development of foreign language teachers. In the future, ESP evaluation system research closely related to ESP teaching should be expanded. The industry will be expanded to cover various aspects of international communication, including agriculture, forestry, animal husbandry, fishing and mining.

2. Deepening research objects

At present, most domestic ESP research focus on the exploration of teaching practice. So some research is still lack of depth. First, the ESP theory should be further studied. Using foreign ESP interdisciplinary research results for reference, a more mature and systematic ESP theory system can be formed, which will be useful for guiding language teaching practice. Secondly, for ESP corpus construction, ESP dictionary construction, ESP teaching material construction, and ESP teacher training, which are just in the initial stage of research, we should continue to strive to obtain research achievements with high value.

3. Utilizing multiple research methods

The comprehensive application of a variety of research methods is conducive to a comprehensive and accurate understanding of the research object. The previous studies were mostly speculative ones, focusing on ESP connotation, curriculum design, or analysis of ESP teaching. Quantitative and qualitative research methods based on data collection and analysis are rare. There are many synchronic studies, mainly focusing on the problems existing in current ESP teaching or analysis of ESP needs. There are few diachronic studies, such as follow-up studies on ESP teaching effects. Therefore, in order to research ESP in a more comprehensive way, future studies need to further combine theoretical speculation with practical exploration, and synchronic research with diachronic research.

\section{CONCLUSION}

In this study, the development process of ESP research in China from 2000 to 2017 was preliminarily demonstrated with the tool of scientific knowledge mapping, and the reasons for the development trend of each time zone were discussed. The research hotspots in this field were analyzed, and the main research results and characteristics were summarized. Future ESP researchers can further expand the research space, such as conducting co-citation analysis of literature, authors and research institutions, tracking the origin and future trend of research in this field and promoting the further development of this research.

\section{REFERENCES}

[1] Cai, Jigang. (2004). ESP and development orientation of college English teaching in China. Foreign Language World 2, $22-28$.

[2] Cai, Jigang. (2014). From general English to academic English — return to college English teaching standard. Foreign Languages and Their Teaching 1, 9-14.

[3] Cai, Jigang. (2015). Review, problems and tasks of ESP teaching in China. Journal of Xi'an International Studies University $23.1,68-72$.

[4] Cai, Jigang. \& Chen, Ningyang. (2013). Analysis of students and faculty's needs for ESP in the context of the Internationalization of higher education. Technology Enhanced Foreign Language Education 5, 3-9.

[5] Cai, Jigang. \& Liao, Chaolei. (2010). ELE vs. ESP-The orientation of college English. Technology Enhanced Foreign Language Education 5, 20-26. 
[6] Chen, Liping. (2001). The basis for existence of ESP. Foreign Languages and Their Teaching 12, 28-30.

[7] Chen, Jinshi. (2011). Interactive ESP reading teaching in autonomous learning environment-A corpus-based practice of discourse information teaching. Foreign Language World 5, 31-39.

[8] Chen, Xiao. (2016). On the ESP teaching mode in the Internet plus era. Journal of Shenyang Agricultural University (Social Sciences Edition) 18.3, 345-349.

[9] Fu, Da'an. (2012). College English teaching reform at common colleges under the framework of ESP. English Studies 10.3, 64-68.

[10] Fu, Da'an. (2016). From EGP instructors to ESP instructors: On teacher role-shift in local universities. Foreign Languages and Their Teaching 3, 21-27+144-145.

[11] Guo, Guihang. \& Li, Dan. (2015). Professional quality and teacher development of business English teachers-Analysis based on ESP needs theory. Journal of PLA University of Foreign Languages 38.5, 26-32.

[12] Guo, Yanling. (2014). The characteristic of pedagogy of ESP "post-method era". Theory and Practice of Education 34.24, 41-43.

[13] Guo, Yanling. (2016). "A learning-centered approach": The post-method era of ESP. Foreign Languages in China 13.6, 74-79.

[14] Gu, Zhizhong. (2006). Applying task-based approach to business English teaching. Shandong Foreign Language Teaching 3 , $77-80+85$

[15] Gu, Zhizhong. (2010). Analysis of current ESP teaching and coping strategies. Technology Enhanced Foreign Language Education 3, 25-29.

[16] Han, Geling. \& Dong, Juan. (2011). On multimodal and ecological college English curricula. Technology Enhanced Foreign Language Education 2, 21-25.

[17] Han, Hongwen. Tian, Hanzu. \& Yuan, Dong. (2012). Characteristics, causes and countermeasures of Homogenization on instructional model of university in China. Educational Research 33.9, 67-72.

[18] Han, Jinlong. (2003). Review of the latest development of ESP. Foreign Language Teaching Abroad 4, 58-63.

[19] Huang, Fang. (2011). College English teaching innovation for cultivating excellent engineering talents-Based on the innovation of University of Shanghai for Science and Technology. Technology Enhanced Foreign Language Education 15.1, $15-19$.

[20] Hutchinson, T. \& Water, A. (1987). English for specific purposes. New York: Cambridge University Press.

[21] Ji, Peiying. (2017). ESP curriculum based on the framework of guide on college English teaching. Foreign Language World 3 , $16-21+56$.

[22] Li, Gesong. (2017). The change of English teaching paradigm and the practice of "new national standard". Foreign Languages Research 34.3, 54-59

[23] Li, Gewei. Ge, Lingling. \& Jiang, Shihong. (2015). Development and application of ESP corpus in the context of internationalization of higher education. Journal of Xi'an International Studies University 23.2, 74-77.

[24] Li, Ming \& Cai, Jigang. (2013). College English teaching reform to cope with a transition-An Interview with Prof. Cai Jigang. Shandong Foreign Language Teaching 34.5, 3-6+2.

[25] $\mathrm{Li}, \mathrm{Na}$. \& Hu, Weihua. (2014). Research on ESP oral teaching design for non-English major graduate students under the guidance of "needs analysis" theory. Foreign Language Education 35.3, 48-51.

[26] Li, Xin. (2016). On English ESP curriculum and teaching model for postgraduates in science and engineering colleges. Academic Degrees \& Graduate Education 4, 23-26.

[27] Li, Xin. (2017). Research on ESP materials development in colleges and universities. Publishing Research 4, 54-56.

[28] Liu, Bin. (2016). The construction and practice of flipped classroom teaching model in medical English. Foreign Language Education 37.5, 62-65.

[29] Lu, Weicheng. (2009). Principles and process of ESP course design and its instruction guidance. Research in Higher Education of Engineering 2, 145-148.

[30] Luo, Weihua. \& Tong, Daming. (2009). ESP teaching and research methods-Take maritime English as an example. Foreign Language World 1, 86-89+9.

[31] Ma, Yan. (2009). Exploring medical English curriculum and teaching from the perspective of ESP - A case study of a medical English teaching .Technology Enhanced Foreign Language Education 1, 60-63.

[32] Sun, Youzhong. \& Li, Liwen. (2011). CBI, ESP and the direction of college English major and college English teaching reform in China. Foreign Languages Research 5, 1-4.

[33] Wang, Beilei. (2004). A survey on ESP teaching in Tongii University. Foreign Language World 2, 35-42.

[34] Wang, Huiting. (2014). A study on the application of project-based teaching method in ESP courses. Chinese Journal of ESP $5.1,38-43+89$

[35] Wang, Lijuan. (2016). On the problems and strategies of ESP teaching. Foreign Language World 6, 57-63.

[36] Wang, Shouhong. Liu, Jinling. \& Fu, Wenping. (2015). A study on the content-based college ESP instruction under the background of MOOC era. China Educational Technology 5, 97-101+120.

[37] Wang, Shouren. \& Wang, Haixiao. (2011).On the state of college English teaching in China and its future development. Foreign Languages in China 8.5, 4-11+17.

[38] Wang, Shouren. \& Yao, Chenhe. (2013). Some thoughts on English for academic purposes (EAP) teaching. Foreign Languages in China 10.5, 4-10.

[39] Wang, Youliang. (2012). Curriculum Design of Business English from the Perspective of ESP Needs Analysis. Journal of Guangzhou University (Social Science Edition) 11.1, 89-93.

[40] Yang, Ting. \& Jin, Chuanmeng. (2015). On the nature, boundary and implementation of school curriculum power. Curriculum, Teaching Material and Method 36.5, 23-28.

[41] Yu, Jiangyao. \& Liu, Fagong. (2013). A review of the curriculum setting of business English major in China. Foreign Languages and Their Teaching 3, 37-40.

[42] Yu, Liming. \& Han, Jianxia. (2012). Content-driven or language-driven?-Some thoughts on college English teaching in China. 
Foreign Languages and Their Teaching 3, 1-4.

[43] Yu, Zhangya. (2011). Practical research and implication on ESP teaching-A case study of "electric power English". Foreign Language World 5, 56-61.

[44] Yu, Zhangya. (2012). Implications of professional English needs survey for college English teaching. Foreign Language World $5,88-96$.

[45] Zhang, Hong. \& Yuan, Sen. (2014). A study of the practice of ESP teachers' training. Theory and Practice of Education 34.24, 34-35.

[46] Zhang, Jihua., Wang, Beilei. \& Gao, Qin. (2009). On corpus-based college ESP teaching. Technology Enhanced Foreign Language Education 4, 38-42.

[47] Zhang, Mulin. (2013). Discussion on IT-based ESP + EGP blended teaching and learning model. Journal of Xi'an International Studies University 21.1, 78-81.

[48] Zhang, Wei. (2015). The interactive model of cognitive pedagogy in ESP teaching. Foreign Language Research 2, $108-111$.

[49] Zhang, Yamei. (2008). Research on ESP English teaching strategies in higher vocational colleges. Chinese Adult Education $128.18,181-182$.

[50] Zhang, Yie. (2011). A preliminary study on military English teaching in armed police colleges based on ESP theory. Education Exploration 51.5, 51-56.

[51] Zhao, Ke. \& Wang, Zhijun. (2015). Towards an ESP approach: Design research in English for business communication at Shanghai university of finance and economics. Foreign Language Learning Theory and Practice 2, 67-72+97.

[52] Zhu, Wenzhong. (2010). Business English teaching mode: Its theoretical evolution, features and performance. Journal of Guangdong University of Foreign Studies 21.4, 22-27.

[53] Zhuang, Xueyun. (2009). Exploration of ESP teaching in English majors in higher vocational colleges. Education and Vocation 20, 106-108.

[54] Zou, Wenli. (2013). The ESP implementation in higher education in Taiwan-Using national Cheng Kung university as an example .Foreign Language Learning Theory and Practice 3, 12-16+94.

Fanghui Hu was born in Jining, China in 1981. She received her Master Degree from Hunan University in 2007.

She is currently a lecturer in School of Foreign Languages, Jining Medical University, Rizhao, China. She has been teaching in Jining Medical University for eleven years; course taught include English listening, Introduction to Linguistics, English writing, and Stylistics. Her research interests include second language acquisition and language testing. 